\title{
Investigation of Power Supply Methods for Intelligent LED Luminary
}

\author{
Alexander Suzdalenko*, Ilya Galkin ${ }^{\dagger}$ \\ * RTU Institute of Industrial Electronics and Electrical Engineering, Riga, Latvia, Aleksandrs.Suzdalenko@rtu.lv \\ ${ }^{\dagger}$ RTU Institute of Industrial Electronics and Electrical Engineering Riga, Latvia, gia@avene.eef.rtu.lv
}

\begin{abstract}
In the context of Intelligent Lighting System various lighting devices and technologies are compared. For the most technically beneficiary and rapidly developing LED luminaries control and power supply methods are analyzed and experimentally tested. The optimal one is chosen. Outlines of the further research are defined.
\end{abstract}

Keywords - Smart Power, Self-sensing control, Adaptive control, Regulation.

\section{INTRODUCTION}

Generally the concept of Smart Grid means enhancement of common electric grid with monitoring, analysis, control and communication capabilities in order to improve reliability, maximize throughput, increase energy efficiency, provide consumer participation in the energy distribution as well as allow diverse generation and storage options[7].

The devices of Smart Grid tend to be efficient in energy consumption field as well as "smart" enough to be able to decide whether the device is working usefully or not. A good example of where the Smart Grid concept should be introduced is an indoor and outdoor lighting. The lighting in municipal as well as in other buildings is often switched on almost all day long in the corridors and staircase, in spite of the need for illumination. The road lighting also is switched on constantly during the night time without any correction depending on traffic density and weather conditions. If the mentioned parameters were monitored and lighting levels were adjusted then the overall consumption of the lighting system could be reduced.

The main goal of the given work is to identify the approaches to the development the energy effective automatically reconfigurable energy systems for the effective control of lighting. This includes elaboration and analysis of power converters for LED luminaries with dimming possibility, analysis of the different LED arrangement in the luminary to achieve uniform light output.

\section{LIGHTING IN MODERN SOCIETY}

The world electricity consumption for lighting in 2005 of $3418 \mathrm{TWh}$ represents $19 \%$ of the world's total electricity consumption of 17982 TWh. Meaningful part of consumed electrical energy is spent for street lighting (for example, in Norway 3\% of all electricity demand). At the same time for an average commercial building the lighting takes about $30-40 \%$ of its electricity bill [2][3]. It is seen that the problem of energy efficiency in lighting is important and topical.
The development of energy effective Street Lighting system is closely related to the three main goals of such systems: 1) providing safety for all type traffic users on road; 2) providing visibility of pedestrians and 3) providing safety for pedestrians. Traffic route lighting is designed for the worst case scenario, i.e. the maximum traffic density on the road. However, many traffic routes have high peak hour traffic for a very short period with substantially lower traffic flows for the remainder of the lighting cycle. In such cases a close examination of the traffic flow patterns and reasonable reduction of lighting at this time may lead to the significant savings in energy use and cost.

One way to get some step closer to preserve the nature is to decrease electrical energy consumption produced by fossil fuels and improve the efficiency of electrical technologies. Since the lighting is widely used all over the world it is needed to improve the efficiency of lighting sources. The electricity consumption in Europe for street lighting alone is estimated to be more than $40 \mathrm{TWh}$ annually. Some known examples [6] shows annual saving of about $30-50 \%$ is attainable by modernizing the luminaries and utilizing intelligent lighting technology.

Energy saving initiatives can be divided into the following groups:

- Replacing inefficient lamps - some lamps, such as incandescent, halogen or high pressure mercury lamps can be converted to a more efficient model such as high pressure sodium, metal halide, or LED;

- Improvement of a luminary characteristic - some luminaries may have more efficient light reflectors to direct light more precisely;

- Replacing of a magnetic ballast - new generation ballast can offer greater efficiencies and opportunity for dimming lights;

- Introduce a distance management for lighting control (dimming); this allows lighting to respond to individual conditions;

Better use of existing infrastructure - some lighting applications need to be improved by adjusting color, lighting class, hours of operation; or complete removal.

\section{INTELLIGENT LIGHTING SYSTEM}

The definition of intelligent lighting assumes a total system with dimmable luminaries, advanced lighting control solutions, communication systems and administrative tools. The solution focuses on reducing energy consumption and high functional standard. It also, in most contexts, automatically declines the maintenance costs for the operator in combination with increased safety for the street user. 
Introducing intelligent lighting means a more complex control of the system. In contradiction to the well known "on/off" technology, the intelligent street lighting requires more sophisticated analysis of the input parameters. The system should automatically react to external factors, such as traffic density and the weather conditions. For example, the level of lighting could be increased when there are a lot of cars travelling on a specific stretch of road. It is also possible to dim the lighting at night when fewer cars or other road users are on the roads or if the surface is covered with snow, but during rainy or fogged weather the lighting level should be increased.

Also Intelligent System can count the burning hours so that changes can be planned based on a statistical approach. Warning notifications can also be generated when the luminaries approach their end of life. The system can automatically report lamp failures. This results in eliminating the need to perform scouting activities to control the lighting.

Intelligent lighting concept is especially attractive in autonomous lighting systems because: 1) it reduces electricity demand due to improved functionality (as explained above); 2) additionally it helps to choose the most suitable renewable energy source; 3) it allows implementation and smart utilization of energy storages.

This new technology is highly energy-efficient and therefore also cost-efficient because it provides light when and where it is needed most of all.

\section{COMPARISON OF LIGHTIN SOURCES}

The efficiency and performance of lamps has been improved dramatically during the last 30 years. Traditional gas discharge lamp control has become more efficient with the move from magnetic ballasts to electronic ballasts. At the same time the lamp technologies has evolved from High Intensity Discharge (HID) Mercury vapor to Sodium and metal halide. The current market of artificial lighting technologies has been widen by new technology - LED (Light Emitting Diode), which can be used to build very efficient and functional lighting source. At the given time lighting efficiency of the LED technology approaches $1001 \mathrm{~m} / \mathrm{W}$. Therefore it could replace some traditional lighting sources like incandescent, fluorescent bulbs and in some applications even HID lamps, because HID lamps always require a reflector, which produces specific form of light beam for uniform surface illumination. On the other hand it leads to some "optical" losses and the real-life efficacy of the HID lamp can be smaller than it is shown in specification. In opposite to all other kinds of lamps LEDs have naturally directed light output that saves lumen losses in reflector.

Since the dimmable luminary is one of the major components of Intelligent Lighting system the various types of lamps were studied for this feature (Table 1).

The table shows that some types cannot be used in Intelligent Lighting system. Dimming of the HID lamps is limited due to the shift of color, reduced color rendering index (CRI) and increased flickering. One more drawback is inadvertent lamp shutdown, after which the lamp needs to be cooled down before reigniting (1-5 $\mathrm{min}$ ), then needs to be switched at rated wattage for a minimum of 15 minutes before the next dimming. In general, dimming HID lamps much below 50 percent is not practically applicable. At the same time LED technology has no negative influence on dimming, even opposite, according to working characteristics of LED their efficacy is higher at reduced power. Beside that LED technology has other unique properties, like these: low voltage power supply, shock resistance, long life, instant starts-up and dimming for up to $100 \%$, which make them indispensable in certain applications. Also this technology improves the color quality that makes it perspective in study and use in purpose of Intelligent Lighting.

\section{COMPARISON LED LUMINARY DIMMING METHODS}

LEDs themselves are low voltage semiconductor elements (diodes) that are not directly compatible with common AC networks. Therefore some converter is always required to supply LED luminary.

If the luminary must provide some constant amount of light its power supply must ensure the corresponding constant current of the LEDs. This can be done with some traditional equipment like voltage source and series balancing resistor or current regulator (more efficient and preferable solution).

Light dimming is only possible with more complex power supply. Preliminary analysis revealed three basic light control approaches: 1) regulation of value of LED's current; 2) pulse width modulation of the current; 3 ) sectional powering of LEDs. Besides that it is possible to combine the first two approaches with the third one.

TABLE I.

COMPARISON OF DIFFERENT LIGHT SOURCES [1][5]

\begin{tabular}{|c|c|c|c|c|c|c|}
\hline $\begin{array}{c}\text { Lamp } \\
\text { technology }\end{array}$ & $\begin{array}{c}\text { Efficacy }(*) \\
{[\operatorname{lm} / \mathbf{W}]}\end{array}$ & $\begin{array}{l}\text { Life time } \\
\text { [hours] }\end{array}$ & CRI & $\begin{array}{c}\text { Available Dimming } \\
\text { Level [\%] }\end{array}$ & Dimming Influence & $\begin{array}{c}\text { Startup } \\
\text { time }\end{array}$ \\
\hline Incand. & $10-17$ & $1 \mathrm{k}$ & 100 & 100 & Positive: lifetime extending & Instantly \\
\hline Halogen & $12-20$ & $2 \mathrm{k}$ & 100 & 100 & $\begin{array}{l}\text { Negative: lifetime shorten - } \\
\text { halogen cycle doesn't work }\end{array}$ & Instantly \\
\hline FL & $20-60$ & $10-20 \mathrm{k}$ & 80 & 10 & Neutral & $1-5 \mathrm{sek}$ \\
\hline MV & $25-40$ & $14-20 \mathrm{k}$ & 80 & 50 & $\begin{array}{l}\text { Negative: Lifetime shorten; } \\
\text { Color shifting }\end{array}$ & $5-7 \min$ \\
\hline MH & $35-50$ & $10-15 \mathrm{k}$ & $60-90$ & 50 & $\begin{array}{l}\text { Negative: Lifetime shorten; } \\
\text { Color shifting }\end{array}$ & $2-5 \mathrm{~min}$ \\
\hline HPS & $55-65$ & $24-32 \mathrm{k}$ & 40 & 80 & Positive: Lifetime extending & $5-10 \mathrm{~min}$ \\
\hline LED & $65-75$ & $50-100 \mathrm{k}$ & $70-90$ & 100 & $\begin{array}{l}\text { Positive: Efficacy risen, } \\
\text { Lifetime extending }\end{array}$ & Instantly \\
\hline
\end{tabular}

* - Typical expected performance in real-life applications. Based on mean lumens, and including ballast/driver, thermal equilibrium and typical fixture Coefficient of Utilization losses. 


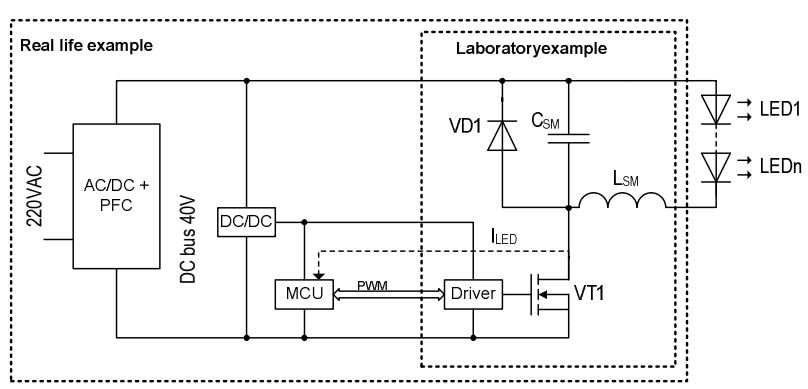

Fig. 1. Current regulator for LED luminary with a buck chopper.

\section{A. Regulation of current}

The current stabilizer of the luminary includes a current feedback with current sensor, error amplifier, PI or PID regulator and power converter. However, it is difficult to find an integrated current regulator while its discrete implementation is bulky. That is why it has been decided to adopt a voltage regulator to the given application.

Such voltage regulators are also designed as closed loop systems, but they include a voltage feedback with voltage divider as a sensor. In steady state mode the regulator ensures $1.235 \mathrm{~V}$ in its midpoint. The upper and lower parts of such divider may be chosen arbitrary, but their ratio defines the output voltage. If the voltage of the midpoint is fixed the divider may be described as a branch with constant current that is defined by $1.235 \mathrm{~V} / \mathrm{R}_{\mathrm{LOW}}$ (where $\mathrm{R}_{\mathrm{LOW}}$ is the value of the lower resistor). Then, the upper resistor may be even non-linear, for example, series of LEDs - its current will also be stabilized.

The proposed example is based on a classical buck chopper (Fig. 1). Its preliminary simulation asks the following choice of the applied elements: $\mathrm{L}_{\mathrm{sw}}=220 \mu \mathrm{H}$, $\mathrm{C}_{\mathrm{sw}}=1000 \mu \mathrm{F}, \mathrm{VT}_{1}=\mathrm{IFRZ44N}, \mathrm{VD} 1-\mathrm{SBL} 1060$.

\section{B. Pulse width modulation of current}

This approach is based on the phenomenon of inertia of the human eye. If a luminary is blinking fast enough then such blinking is recognized as dimming. The depth of the dimming depends on the duty cycle of the signal. There are several possible realizations of this approach.

- Direct PWM signal may be applied to the transistor commutating DC voltage to the connected in series LEDs and balancing resistor.

- Inverted PWM signal may be applied to the transistor short-circuiting the series connection of LEDs.

- Direct PWM signal may be used as enable signal for the current stabilizing IC [1].

For laboratory testing the first approach was used. PWM signal was taken from a laboratory signal generator and through a driver circuit applied to the transistor.

\section{Commutation of groups}

If the luminary contains few lighting devices they can be controlled in groups thus providing several steps of lighting. Utilization of the binary weighted groups gives more levels of lighting with more constant step. Each group of LEDs requires its own power supply that, however, may be less complex (3 laboratory power supplies were used in the experiments) [1].

In the given research 7 LEDs in three groups of 1, 2 and 4 diodes are used (Fig. 3-a and Fig. 3-b). Then there are 7 available levels of power and brightness (Fig. 3-c).

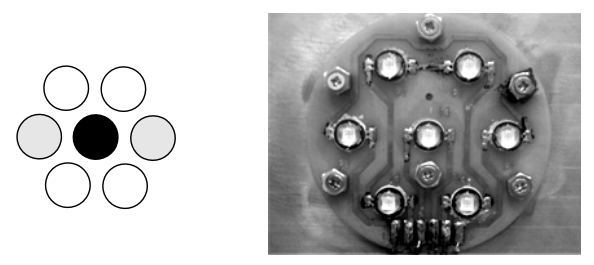

a) configuration

b) laboratory example

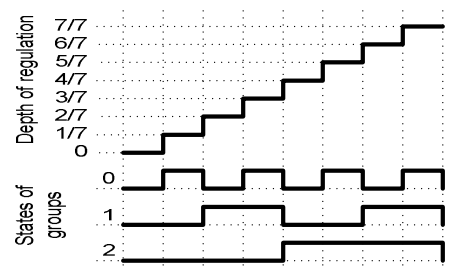

c) operation

Fig. 3. Grouping of lighting elements in the 70W 7 LED luminary.

\section{EXPERIMENTAL RESULTS}

The mentioned approaches were tested with 70W LED luminary that consists of 7 W724C0 LEDs (2.8A, 10W $\sim 80 \%$ of which is released as heat), the corresponding heatsink and connectors available for each binary weighted group of LEDs. The experiments were made in order to find the most energy saving and cost effective solution, as well as to uncover the properties of dimming methods and their efficiency.

Experimental data were firstly taken for group switching method by measuring the illumination level for all available LED combinations. After that the current regulation and current PWM methods were tested. The measuring points were chosen in correspondence with first test by changing regulation parameter (current level for current regulation and duty cycle for PWM approach).

Typical light distribution over the explored surface is presented in Fig. 4. As it was expected the measured brightness is maximal just under the luminary and drop significantly (about $20 \%$ per $1 \mathrm{~m}$ ) across the distance. No other significant light spots or shadows are found. In whole this is typical lighting picture for luminary without reflectors, diffusers or other light equalization means.

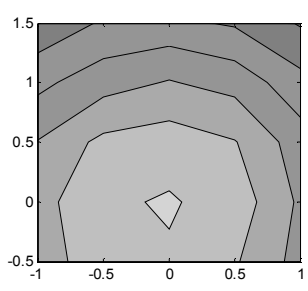

a) group switching

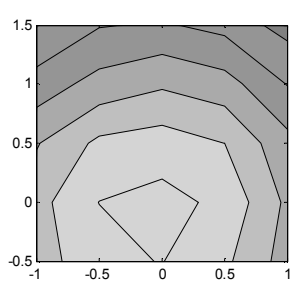

b) current PWM

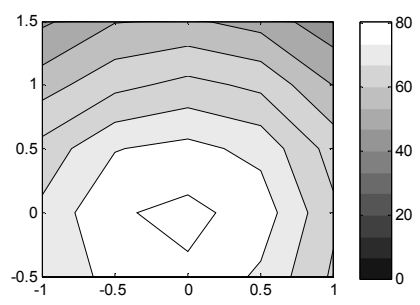

c) current regulation

Fig. 4. Illuminance at $3 / 7$ of control parameter 
TABLE II.

AVERAGE BRIGHTNESS [LX] AT DIFFERENT VALUES OF CONTROL PARAMETER AT DIFFERENT POWER SUPPLIES

\begin{tabular}{|c|c|c|c|c|c|c|}
\hline 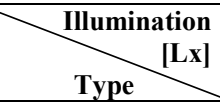 & 202 & 403 & 610 & 768 & 958 & 1166 \\
\hline $\begin{array}{c}\text { Grouping } \\
(\text { LED count / 7) }\end{array}$ & 0,14 & 0,29 & 0,43 & 0,57 & 0,71 & 0,86 \\
\hline $\begin{array}{c}\text { PWM } \\
\text { (Duty cycle \%) }\end{array}$ & 0,12 & 0,26 & 0,39 & 0,51 & 0,65 & 0,82 \\
\hline $\begin{array}{c}\text { Current control } \\
\text { (I/Imax) }\end{array}$ & 0,09 & 0,20 & 0,32 & 0,43 & 0,57 & 0,75 \\
\hline
\end{tabular}

TABLE III.

LED WORKING TEMPERATURES $\left[{ }^{\circ} \mathrm{C}\right.$ ] AT DIFFERENT POWER SUPPLIES

\begin{tabular}{|c|c|c|c|}
\hline $\begin{array}{r}\text { Illumination } \\
\text { Typ] }\end{array}$ & $\mathbf{2 0 2}$ & $\mathbf{6 1 0}$ & $\mathbf{9 5 8}$ \\
\hline Grouping & 96 & 96 & 103 \\
\hline PWM & 36 & 51 & 79 \\
\hline Current control & 42 & 63 & 79 \\
\hline
\end{tabular}

TABLE IV. CONSUMED POWER [W] AT DIFFERENT POWER SUPPLIES

\begin{tabular}{|c|c|c|c|c|c|c|c|}
\hline Type & $\mathbf{2 0 2}$ & $\mathbf{4 0 3}$ & $\mathbf{6 1 0}$ & $\mathbf{7 6 8}$ & $\mathbf{9 5 8}$ & $\mathbf{1 1 6 6}$ & $\mathbf{1 3 6 2}$ \\
\hline Grouping & 10.0 & 19.2 & 28.6 & 37.5 & 46.3 & 56.0 & 65.0 \\
\hline PWM & 14.1 & 22.9 & 29.9 & 35.9 & 44.4 & 53.4 & 62.6 \\
\hline $\begin{array}{c}\text { Current } \\
\text { control }\end{array}$ & 5.1 & 11.5 & 18.8 & 25.8 & 35.0 & 47.0 & 63.0 \\
\hline
\end{tabular}

The similar picture could be presented for the other values of the regulation parameter. However, it is more important to compare brightness at different control approaches and at different levels of the corresponding control parameter that is done in Table II. It is obvious from this table that switching of groups and PWM provides quite linear regulation $(3.5 \%$ and $4 \%$ respectively) while current regulation is highly non-linear $(10 \%)$. This phenomenon could be explained by nonlinear lighting characteristic of LED itself.

Another table (Table III) represents the operating temperature of LED package. It shows that in PWM and current control modes the temperature depends on operation parameter, but in group switching mode operating LED temperature is about $100^{\circ} \mathrm{C}$. The next significant comparison is a comparison of the consumed power (Table IV). From this table it is seen that current regulation consumes less power for the same level of control parameter. PWM approach is the most power consuming. However, it must be noted that these data depend a lot on the power calculation methodology and other PWM methods may be more effective.

\section{CONCLUSIONS}

So far the described experiments demonstrate the effectiveness of the current control method. This conclusion has two sides. The first one, the lower is current the higher is efficacy of diodes $[\mathrm{lm} / \mathrm{W}]$. The second - lower current leads to the reduced operating temperature of LEDs and, hence, to higher light output (smaller losses). The performance of all control methods is summarized in Fig.5.

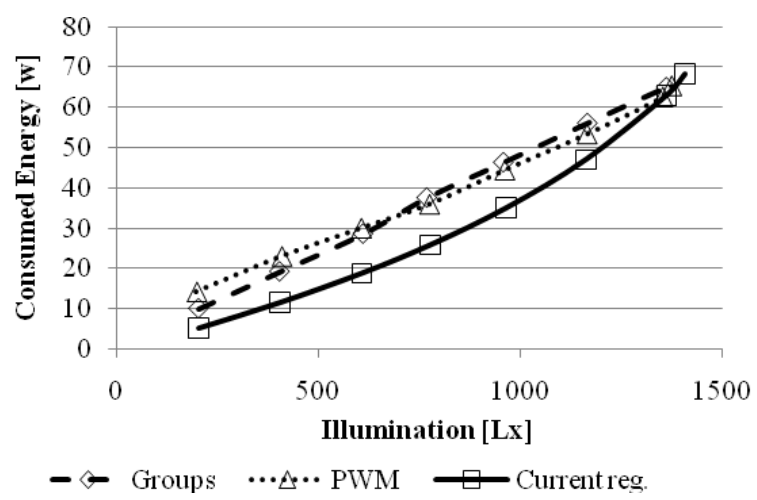

Fig. 5. Efficiency of dimming control methods

All LEDs have the same drawback - their lifetime directly depends on the operating temperature. Therefore the current control and PWM approaches are more preferable also from this point of view.

Besides the dimming capabilities LED luminaries have an advantageous control characteristic - small reduction of illumination corresponds to significant reduction of consumed electrical energy (Table V).

TABLE V.

ENERGY SAVINGS BY DIMMING SON AND LED LUMINARIES[4]

\begin{tabular}{|c|c|c|}
\hline $\begin{array}{c}\text { Reduced } \\
\text { Illumination by } \\
\%\end{array}$ & $\begin{array}{c}\text { Energy Savings } \\
(\text { SON }) \\
\%\end{array}$ & $\begin{array}{c}\text { Energy Savings } \\
(\text { LED) } \\
\%\end{array}$ \\
\hline 10 & 6 & 18 \\
\hline 20 & 16 & 30 \\
\hline 30 & 24 & 45 \\
\hline 40 & 32 & 55 \\
\hline 50 & 40 & 65 \\
\hline
\end{tabular}

These data mean that the same dimming realized with LEDs has more than $50 \%$ higher energy saving effect if to compare with SON lamps.

The results of the conducted experiments confirm the advisability of utilization of LED technology in Intelligent Lighting Systems. They also allow recommending the development of power converters and information support for Lighting Systems with LEDs

\section{REFERENCES}

[1] Давиденко Ю. Н. 500 схем для радиолюбителей. Современная схемотехника в освещении. Эффективное электропитание люминисцентных, галогенных ламп, светодиодов, элементов «Умного дома». - СанктПетербург: Наука и Техника, 2008. - 320.lpp.;

[2] Lester R. Brown: "Plan B 4.0: Mobilizing to Save Civilization" - New York: W.W. Norton \& Company, 2009 - ISBN 978-0393-07103-0;

[3] IEA (2006a) Light's Labor's Lost. International Energy Agency, OECD, Paris;

[4] International Municipal Signal Association - Adaptive Roadway Lighting/ IMSA Journal 2006.g. 54. - 58.lpp. http://www.imsasafety.org/journal/so06/18.pdf;

[5] Dr. John W. Curran - 100000 hour lifetime and other LED fairytales / LightFair seminar - 2008 http://www.ledtransformations.com/Lightfair 5-28-08.pdf;

[6] Northern Ireland Assembly - Energy Efficiency in Street Lighting / Research paper 30/09 - 2009. 12 March;

[7] National Institute of Standards and Technology SmartGrid site http://www.nist.gov/smartgrid/. 